\title{
The Effect of Absence of Thumb on Palmar Dermatoglyphics*
}

\author{
SARAH B. HOLT \\ Galton Laboratory, University College London
}

When a hand has no thumb ridge configurations in the proximal palm are distorted. There is no axial triradius, and the ridges run transversely across the palm. This unusual arrangement was reported in German cases of thalidomide poisoning by Pfeiffer and zu Berge (1964). Since that time the characteristic alignment has been found not only in English cases of thalidomide poisoning with radial dysplasia, but in similarly deformed hands of patients with varying chromosomal aberrations.

Fig. 1 shows the right hand of an English case of thalidomide poisoning. There is no thumb, but all the other digits are present. The axial triradius is absent and the alignment of the ridges in the proximal part of the palm is transverse. On this palm the courses of the main lines $B, C$, and $D$ are anomalous; all terminate on the radial border. This peculiarity is not found in all cases of radial dysplasia. However, such an arrangement is not uncommon on the hands of children suffering from thalidomide poisoning.

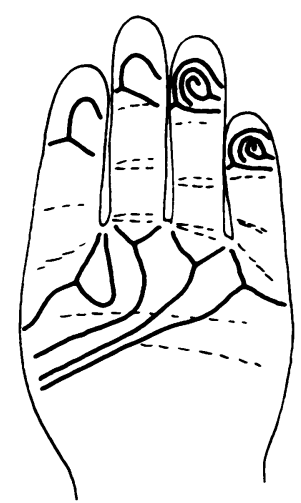

FIG. 1. Thalidomide poisoning: main lines and type lines on the right hand of a child.

\footnotetext{
Received 14 August 1972.

* Paper given at the Symposium on Dermatoglyphics at the IVth International Congress of Human Genetics, Paris, September 1971.
}

The hands of another case of thalidomide poisoning are shown in Fig. 2. On both the thumb is missing and the characteristic transverse orientation of the ridges in the lower sections of the palms is apparent. On the right hand there is an ulnar triradius associated with a radial loop. Only 3 fingers are present on the left hand and the only triradii on the palm are 2 interdigital ones. Both hands show the radial direction of the main lines, as in Fig. 1.

Fig. 3 shows the hands of another child suffering from thalidomide poisoning. The left hand is normal with all 5 digits and there is nothing anomalous

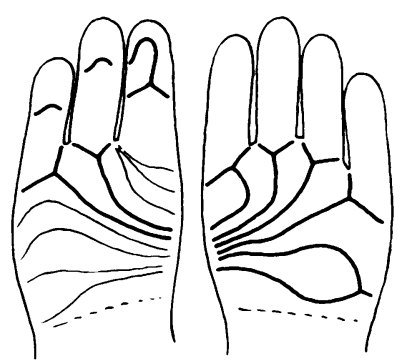

FIG. 2. Thalidomide poisoning: main lines on left and right hands.

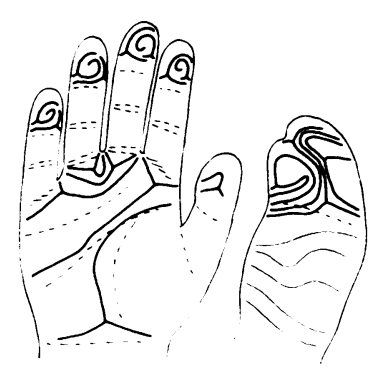

FIG. 3. Thalidomide poisoning: main lines and type lines on left and right hands. 
about the dermatoglyphics. In contrast, the right hand is badly deformed and hardly recognizable as a hand. The 2 digits are fused (syndactyly) and there is a characteristic interdigital triradius. Ridges run transversely across the palm and there is no axial triradius.

Fig. 4 is a drawing of the right hand of a patient with multiple congenital abnormalities described by Adams (1965). The karyotype was abnormal, one of the 6 chromosomes in the 13-15 (D) group being a ring chromosome. There is no thumb and the ridge alignment in the proximal palm is similar to that in the foregoing cases of thalidomide poisoning.

Fig. 5 shows the hands of an infant patient of $\mathrm{Dr}$ Gouw with an abnormal sex chromosome complement (details not known). Thumbs are absent bilaterally and the ridge arrangement over each palm is transverse. Axial triradii are absent.

The dermatoglyphics in a case of radial dysplasia reported by Mulvihill and Smith (1969) are shown in Fig. 6. Unfortunately, the cause of the deformity

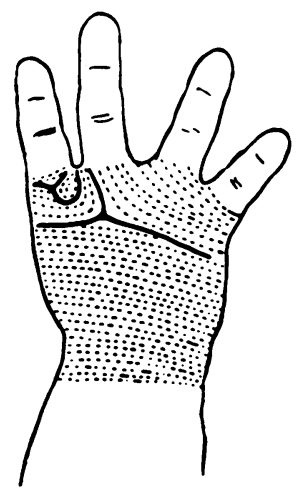

FIG. 4. Palmar dermatoglyphics of the right hand of a patient with a ring-D chromosome (Adams, 1965). (Courtesy of The Lancet.)

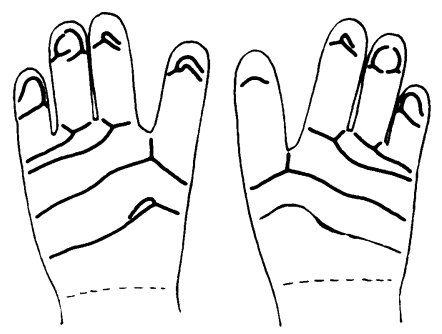

Fig. 5. Hands of infant with abnormal sex chromosome complement.

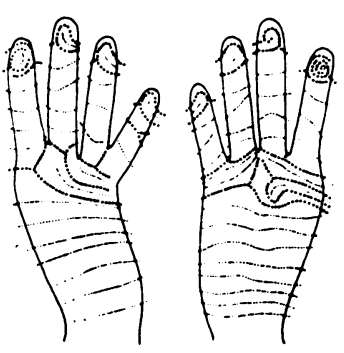

FIG. 6. Dermatoglyphics of the palms and fingers in a case of radial dysplasia (Mulvihill and Smith, 1969). (Courtesy of fournal of Pediatrics.)

is not stated. The ridge arrangement in the proximal area of each palm is characteristic.

From these observations, it appears that when a hand has no thumb, whether all the other digits are present or not, the alignment of ridges in the proximal palm is similar. Moreover, whether the cause of the defect is genetical or not, the dermatoglyphics are characteristic.

The first assumption is that there is some connection between the axial triradius and the thumb. We can go further than this. In all these conditions there is no thenar eminence and this implies that in the fetus there was no volar pad in this position. In a normal hand the ridges curve longitudinally over the thenar eminence and provide one of the 3 ridge systems necessary for the formation of a triradius. The curvature is associated with the presence of a fetal volar pad. In the absence of a pad, the ridges form transversely to the longitudinal growth axis. It seems reasonable to conclude that the peculiar and characteristic alignment in the proximal palm when the hand is thumbless is due to absence of a thenar volar pad at the time of a ridge formation.

Additional evidence in favour of these conclusions is provided by the dermatoglyphics in cases of ectrodactyly ('lobster claw') due to a dominant gene described by MacKenzie and Penrose (1951). Hands with thumbs, although grossly malformed, had axial triradii, whereas hands without thumbs had not and showed transverse alignment of the ridges over the palms (see Fig. 7).

It is interesting to compare the dermatoglyphics of persons with abnormally long thumbs. Bellelli (1937 and 1939) reported gross distortion in men with triphalangy of the thumbs, a form of polydactyly. Two brothers, both with elongated thumbs on right and left hands, had transversely orientated ridges in the proximal areas of the palms, axial triradii in the usual position $(t)$ being absent. 

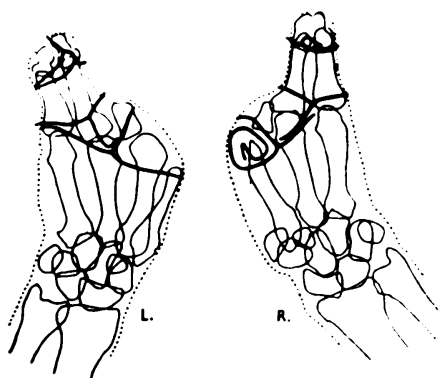

IV. 31 (E.P.). Loft and right hande.
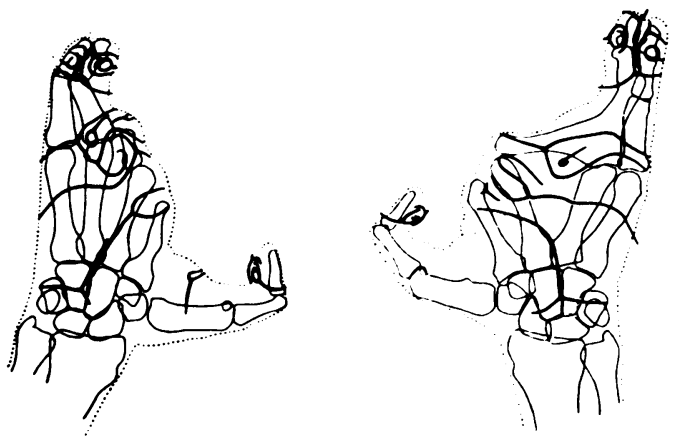

VI. 13 (J.F.A.). Loft hand.

Fig. 7. Ectrodactyly: dermatoglyphic distortion shown in relation to skeletal malformation of the hands (Mackenzie and Penrose, 1951/1952). (Courtesy of Annals of Eugenics.)

On the left palm of one brother there was a triradius in the first interdigital area, presumably indicative of polydactyly. On each of the other palms there was what may, perhaps, be considered a distal axial triradius displaced in a radial direction. It is significant that Bellelli pointed out that in this anomalous condition thenar eminences were poorly developed.

The palm prints of children with thalidomide poisoning used for Figs. 1, 2, and 3 are part of a series sent me by $\operatorname{Dr} R$. W. Smithells for dermatoglyphic analysis.

I am grateful to Dr M. S. Adams and the Editor of The Lancet for allowing me to reproduce the illustration shown in Fig. 4, to Dr J. J. Mulvihill, Dr D. W. Smith, and the publishers of fournal of Pediatrics for permission to use the illustration in Fig. 6, also to the late Professor L. S. Penrose for allowing me to use the one from Annals of Eugenics shown in Fig. 7.

\section{REFERENCES}

Adams, M. S. (1965). Palm-prints and a ring-D chromosome. Lancet, 2, 494-495.

Bellelli, F. (1937). Su alcuni casi di pollice a tre falangi. From Bollettino della Scuola Superiore di Polizia e dei Servizi Tecnici Annessi, nos. 24, 25, and 26 (1934, 1935, and 1936).

Bellelli, F. (1939). Un nuovo caso di pollice a tre falangi bilaterale. Riforma Medica, 18, 1001-1002.

MacKenzie, H. J. and Penrose, L. S. (1951). Two pedigrees of ectrodactyly. Annals of Eugenics, 16, 88-96.

Mulvihill, J. J. and Smith, D. W. (1969). The genesis of dermatoglyphics. Fournal of Pediatrics, 75, 579-589.

Pfeiffer, R. A. and Berge, U. S. zu (1964). Untersuchungen zuro Frage der Handleisten und Furchen bei Extremitätenmissbildungen. Zeitschrift für Konstitutionslehre, 37, 677-712. 